\title{
Social and Economic Burden of Cancer on 2020-Minireview
}

\author{
Vairakannu Tamizhazhagan ${ }^{1}$, Kannaiyan Pugazhendy ${ }^{1}{ }^{\text {*, }}$, Veerasamy Sakthidasan ${ }^{1}$, \\ Chokkalingam Jayanthi ${ }^{2}$, Selvaraj Rajesh ${ }^{3}$, Perumal Manikanadan ${ }^{4}$ \\ ${ }^{1}$ Department of Zoology, Annamalai University, Tamilnadu, India \\ ${ }^{2}$ Department of Education, Annamalai University, Tamilnadu, India \\ ${ }^{3}$ Department of Zoology, Presidency College, Chennai, Tamilnadu, India \\ ${ }^{4}$ Department of Microbiology, Annamalai University, Tamilnadu, India
}

Email address:

tamilzoon@gmail.com (V. Tamizhazhagan),pugalendy@gmail.com (K. Pugazhendy)

${ }^{*}$ Corresponding author

\section{To cite this article:}

Vairakannu Tamizhazhagan, Kannaiyan Pugazhendy, Veerasamy Sakthidasan, Chokkalingam Jayanthi, Selvaraj Rajesh, Perumal Manikanadan. Social and Economic Burden of Cancer on 2020-Minireview. Cancer Research Journal.

Vol. 6, No. 1, 2018, pp. 10-15. doi: 10.11648/j.crj.20180601.12

Received: November 13, 2017; Accepted: November 24, 2017; Published: January 5, 2018

\begin{abstract}
Natural products have been provided as a rich source of a lead compound for drug development against an extensive array of biological targets including an assortment of forms of cancer. Induction of apoptosis as an involuntary cell passing amalgamation for wiping out superfluous cells in tissues is a part of the effectual strategies to the kill of tumor and cancer cells. The current scenario conventional medicinal plant is becoming a popular use of various disease treatments, preventive medicine, and health promotion generally categorized as alternative or complementary medicine in the contemporary scenario. Herbal medicine contains be exploited by indigenous people for generations to treat many different health conditions such as hay fever, bad-tempered bowel syndrome Menstrual Problem and skin conditions currently there is great public interest in finding herbal medicinal plant species to cure major diseases like cancer. Plants have been noteworthy role in as long as the human competition with remedies. The World Health Organization (WHO) has participated that the numeral of new cancer cases will go to 15 million by the year 2020. Cancer is dependable for $12 \%$ of the world's mortality and the second-leading effect of death in the Western world. Communicable and communicable diseases limited chances for a cure by chemotherapy are a most important contributing factor to this typical situation. This review reports motivates to young pharmacy and Life Science field.
\end{abstract}

Keyword: Apoptosis, Cancer, Chemotherapy, Remedies, Medicinal Plant

\section{Introduction}

Mortality outstanding cancer is becoming unacceptably high and is, therefore, a worldwide anxiety. Statics indicate that a total integer of cancer death in 2007 was 7.6 million, of which $62 \%$ were in budding countries and $38 \%$ in residential countries [1]. In ancient raw products have served as a rich resource of the show the way compounds for drug enlargement against a wide array of biological targets including a variety of forms of cancer. Rummage approximately continuous in rigorous footing to notice unexplored plants and animals as potential innovative sources of anticancer drugs [2]. Disproportionate free radicals may produce oxidative constant worry that can damage lipids, proteins and DNA resulting into various chronic and degenerative diseases and or disorders such as cancer cardiovascular, Alzheimer and aging etc., [3]. Antioxidant derivative on or after plants particles are supposed to be protected given that they are natural in preparatory point and have the capability to frustrate the harmful consequence of thoughtless oxygen species ROS [4]. Oxidative constant worry induces a cellular redox imbalance which has-been pragmatic in a mixture of cancer cell lines. The Polyphenols takes account of existing exposed to inhibit the cancer-associated enzyme telomerase, cell cycle and induced apoptosis [5]. Chemotherapy which is a chemical based therapy remains the main mortality for management 
against highly developed stages of the cancers, two main issues encountered in cancer chemotherapy are the development drug resistance and presence of toxic elevation effects which reduce drug efficacy [6].

Cancer is multifaceted multifactorial cell diseases characterized by nonstandard cellular proliferation Cancer expansion and headway are dependent on the cellular accretion of a variety of genetic and epigenetic dealings in human beings [7-8]. Cancer development is usually caused by ontogeny-tumor suppressor gene and micro RNA gene alteration [9]. Accumulating evidence suggests that progress of cancer is mostly triggered by external factors of environmental factors (90\%). These include smoking (30\%), diet and obesity (35\%), infection $(20 \%)$, radiation $(10 \%)$ and stress and environmental pollution (5\%) while the genetic factors contribute only $(10 \%)$ to the cause of cancer [10]. Induction to of apoptosis an involuntary cell death mechanism for wiping out unnecessary cells in tissues is distinctly of the constructive strategies to slaughter cancer cells [11]. Plants have been noteworthy accountability in on condition that the human race with remedies. At present phototherapy is a documented complementary and substitute medicine (CAM) therapeutic modality [69]. It is one of the promising finds in health care as supportive medicine in the treatment of diseases like cancer [12]. Medicinal plants are well thought-out as potential sources of drug and many novel food stuff seen compass reach experimental trials scientist are investigating properties of therapeutic plants in arrange to develop novel drugs against disease like cancer from natural products. Medicinal herbs insightful scope and have been applied to find potential anti-cancer compounds items. Numerous cancer researchers for the chemotherapeutic impending of the medicinal plant has-been agreed out of an effect to discover novel therapeutic agent associated with current therapeutic agents [13]. Lively phytochemicals can be derivative from any part of plant-like park leaves, flowers, roots, fruit, seed, and so forth. Numerous effectual anticancer and antioxidant agents in progress user in experimental trials for anti-cancer activity be the inaccessible beginning ordinary source or are associated to them [14-15]. Cancer is most important causes of death worldwide breast and prostate cancer are two of the majority well-known malignancies and make a payment considerably to the social and financial weigh down of cancer about 10 million newfangled cases are diagnosed and over 6 million deaths happen worldwide per annum, not including non-melanoma skin cancer [16].

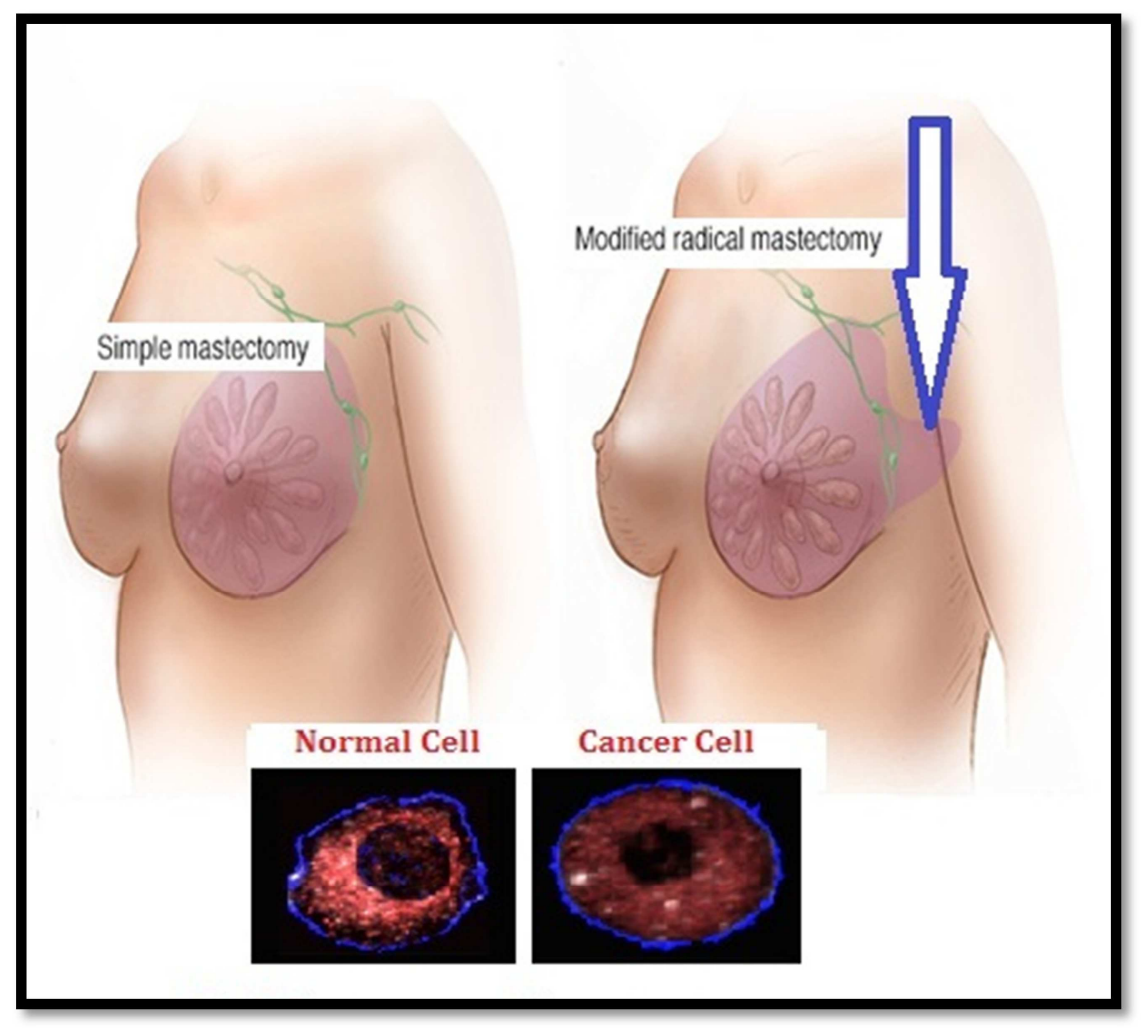

Source: American Cancer Society

Figure 1. Breast cancer and normal cell moderate structure.

Breast cancer is an important worldwide health issue is considered as the most common malignancy and the most widespread grounds of cancer-related bereavement in the western country [17]. In the Structure of Figure 1 normal and cancer cells are clearly exposed anti-cancer agents induced cell succession arrest and or cell death by apoptosis or on apostolic mechanisms together with necrosis senescence, autophagy and mitotic catastrophe [18-19]. Natural products 
determination thus carries on to engage in recreation a most important role as active substance, model molecules for the unearthing and corroboration of drug target [20, 21]. Antioxidant enzymes make up the first line against protection alongside oxidative constant worry and smash up caused by free radicals. When there is a disproportions and witched between oxidative stress and antioxidant enzymes, then there is a possibility that disease such as malignancy, an autoimmune disorder, aging, cardiovascular and neurodegenerative sickness may construct [22-23]. Roughly 80 percentages of the world's residents at a standstill depend on conventional medicine for the treatment of widespread poor health [24]. It is seen that management of cancer and infectious diseases always obligatory a rummage around for new-fangled drugs. Although plentiful drugs are at this point in use for cancer chemotherapy they exhibit cell toxicity induces the genotoxic, carcinogenic and teratogenic effect in no tumor cell [25]. In Indian scheme for pills, the plant hasbeen recognized as thermogenic, purgative, expectorant, diuretic and worn in the treatment of leprosy, erysipelas ulcer, cough, bronchitis, constipation, flatulence, dyspepsia, menstrual troubles tuberculosis and anemia [26]. Natural products have in time go by and incessantly been investigated for shows potential new leads in the pharmaceutical expansion. Cancer is the most significant public health predicaments worldwide with millions of additional cancer patients diagnosed each year and much death consequential from this illness. Chemotherapy oddments the principal method of handling for an assortment of cancers. Researchers have paid critical attention to the anticancer activity of the plants for the motivation that of the treatment and anticipation of Cancer [27-28].

\section{Current Burden of Cancer}

Nowadays conventional medicinal plants are fetching additional popular with use in disease behavior, preventive medicine, and health encouragement and normally categorize as alternative or harmonizing medicine. Herbal medicine had been used by aboriginal working class of generations to treat numerous poles apart health environments such as hay fever, irritable bowel syndrome menstrual predicament and skin circumstances currently there is great public interest in pronouncement herbal medicinal plant species to cure major disease like cancer [29], which is one of the most significant causes of human deaths. The World Health Organization (WHO) has participated that the numeral of new cancer cases will reach 15 million by the year 2020 [30]. Cancer refers to malignant tumors that can make obvious both the local invasion of tissues and distant spreading through the body via the development of metastasis. The growth of cancer cells depends not only on the rate of cell division but also on the rate of cellular slow destruction [31]. Apoptosis is documented as a mechanistically ambitious form of the cell death in the rejoinder to specific stimuli or by commencement following an assortment of forms of cell injury or constant worry [32]. Many conservative plants approximately the world has been second-hand for cancer treatment and a number of these have newly been ascription to be particularly to show impending plausible candidate [3337]. Some ordinary harvested compasses been urbanized for use for cancer therapy and control of inflammation in animal together with flowing anthracyclines (doxorubicin, daunorubicin, epirubicin, inhibition) Vinca alkaloids (vinblastine, vincristine, vindesine, vinorelbine) taxman (paclitaxel, docetaxel) and podophyllotoxin and it is derivative (topotecan, irinotecan) [38-39]. Phytotherapy is a multi-targeted move toward where multiple secondary metabolites exert an antagonistic or a synergistic consequence of a concluding therapeutic rejoinder [40]. Therefore, complex removes with manifold molecules captured in harmonizing behavior could be rehabilitated into a successful rehabilitation for cancer. Nevertheless, using multifaceted phytotherapeutics has a job for chemical categorization for quality control, protection, and effective [41]. For instance, the frequency of breast cancer in India is placed on the rise and is rapidly becoming the numeral one cancer in females approaching cervical cancer to the additional blemish. The number of women predictable to be dying of breast cancer every year has also been progressively increasing.

\section{Cancer Data onto India}

As in opposition to an unsurprising 48,170 women who succumbed to breast cancer in 2007 , the number breached the 50,000 mark in 2010. Uttar Pradesh records the uppermost quantity of breast cancer deaths among Indian states in 2010, 8,882 followed by Maharashtra (5,064), Bihar (4,518) West Bengal (WB) $(4,095)$ Andhra Pradesh (AP) $(3,863)$ Madhya Pradesh (MP) (3,179) and Rajasthan (3,097) [42]. Antioxidants are compounding that can impediment or hold back the oxidation of lipids or other molecules by inhibiting the commencement or broadcasting of oxidative chain reaction [43] Phenolic acids holdover and over an additional time been in a meeting as ordinary antioxidants in various plant parts like fruits, [69] vegetables, and other plants. Rosmarinus acid, an imperative phytochemical [69] 1, has been established to be a potent active substance in opposition to human immunodeficiency virus type 1 (HIV-1) [44]. Cancer is a leading cause of death due to lack of early recognition methods and poor prognosis when detected late especially in on the increase countries. Breast cancer is a very prominent cause of mortality among women worldwide [45]. Oxidative stress, resulting from an imbalance between configuration and neutralization of exceedingly reactive free radicals is worried in carcinogenesis [46]. Plants are well known for surround a diverse assortment of secondary metabolites including anti-cancer compounds and more than a few antioxidants. Natural antioxidants such as flavonoids and polyphenols are studied for their anti-oxidative property of hydrogen donating, radical scavenge and metal chelation behavior of anticipation and treatment of cancer. Therefore considerable concentration has-been heading for towards the 
advance of work of fiction anticancer drugs on or after plant source [47-51]. Cancer is in charge of $12 \%$ of world mortality and one of the second-leading causes of death in the Western world. Incomplete chances of a cure by chemotherapy are an extremely significant contributing factor to this state of affairs. Despite considerable advancement in recent years, a key predicament in tumor therapy with recognized cytostatic compounds is the enlargement of drug resistance and frightening side effects. Most documented drugs knowledge from inadequate specificity in the direction of tumor cells. Hence, the acknowledgment of enhanced anti-tumor drugs is assigned away needed [52]. Obviously $69 \%$ of anticancer drugs standard sandwiched between the 1980s and 2002 are to spontaneous harvest or urbanized based on acquaintance gained from organic harvest [53]. Cancer is a part of the leading causes of morbidity and death in worldwide, despite huge efforts of scientific researchers from an assortment of discipline intended for ameliorating the dismal conclusion of cancer mortality. The rate of death from cancer has not declined significantly even with advances in surgery, radiotherapy, and chemotherapy. Prevention of cancer remains evidently crucial part of the context adjacent to cancer in the world [54-55]. Cancer cells are the result of antiquarian fold genetic disorder that may arise from experience in ecological and professional carcinogenic agents or dietary habits and communicable agents [56]. Nonnutritive biologically full of life chemical compounds in plants which do something as a natural defense system for host plants and provide colour, aroma and flavor [58] According to the topical research of American cancer society, breast cancer is the majority ordinary cancer among American women after skin cancer and it is the most important cause of cancer death in women, exceeded only by lung malignancy. Reference1 in $8(12 \%)$ women in the US will develop invasive breast cancer during their natural life [59]. Breast cancer is the pervasive type of cancer to have an effect on worldwide women, accounting for $23 \%$ of all cancer diagnoses and $14 \%$ of cancer-related death [60]. An assortment of hereditary and environmental factors, together with family history and Westernized diet, is regarded as the major risk factors for breast cancer, but the exact cause is still not predictable [61]. Breast cancer can be classified according to the appearance of hormone receptors, in concert with estrogen receptor (ER), progesterone receptor (PR), and human epidermal enlargement factor receptor 2 (HER2). ERnegative breast cancers, which make up almost $25 \%-30 \%$ of all breast cancers, have a poorer projection than that of ERpositive cancers [62-63]. The plants can manufacture various metabolic compounds for the most part of during the resultant metabolites plant extract to contain several compounds that have a biological dynamic which worn as native medicine [64]. Bioactive compounds are in universal accumulated as secondary metabolites in each and everyone plant cells excluding their attentiveness vary depending on the plant parts [65]. The World Health Organization (WHO) is estimated that almost $75 \%$ of World's populations has therapeutic familiarity with herbal drugs. Cancer is one of the most perilous diseases in humans and presently there is a substantial systematic unearthing of novel anticancer agents from organic harvest [66]. The plants were different medicinally in a developed country and the highest population presented a country like China, India, Egypt, and Greece elongated before the establishment of the Christian era. Drugs such as acacia, castor oil and fennel are only talking about besides with obvious allusion to such compounds as iron oxide, sodium chloride, sodium carbonate and sulfur. Charaka made fifty (50) groups of ten herbs both of them adequate for a commonplace physician's demand. Sushruta arranged 760 herbs in 7 dissimilar sets based on some of their prevalent properties [67]. Cancer represents an infection which occurs when change in a group of standard cells within the body lead to unrestrained growth, causing a lump called a tumor; this is true of all cancers except leukemia (cancer of the blood). If left unprocessed, tumors can grow and multiply into the neighboring normal tissue or to other parts of the body via the bloodstream and lymphatic systems and can have an impact on the digestive, nervous and circulatory system [68].

\section{Conclusion}

In the currents scenario, an assortment of infectious and non-communicable diseases is implemented in World. It may be achieved by researchers' good novel drugs design and drug development against Cancer Treatment. This review to initiate maintenance drug amalgamation may use this review approach in future studies and give an idea of pharmacy and life science researchers.

\section{Acknowledgements}

We wish to acknowledge the help given by Facility Professor and Head, Department of Zoology, Annamalai University, Tamilnadu, India. And also funding Provide Tamilnadu Adhi Travidar Welfare Department, Ezhilagam, Chennai.

\section{References}

[1] American Cancer Society. Global cancer facts and figures 2007. Atlanta: American cancer society 2007.

[2] Moirangthem DS, Laishram S, Chandra Borah J, Chandra Kalita $\mathrm{M}$ and Chandra Talukdar N. Cephalotaxus griffithii hook. f. Needle extract induces cell cycle arrest, apoptosis, and suppression of hTERT and hTR expression on human breast cancer cells. BMC Complementary and alternative medicine, 2014. 14:305 pp-1-10.

[3] Pham-Huy LA, He H, Pham-Huyc C. Free radicals, antioxidant in disease and health. Int J Biomed Sci. 2008.4:8989.

[4] Misra A, Kumar S, Bhargava B, Pandey A K. Studies on in vitro antioxidant and antistaphylococcal activities of some important medicinal plants. Cell Mol Biol. 2011.57: 16-25. 
[5] Naasani I, Seimiya H, Tsuruo T. Telomerase inhibition, telomere shortening and senescence of cancer cells by tea catechins. Biochem Biophys Res Commun. 1998.249:391396.

[6] Nurhanan MY, Nor Azah MA, Zunoliza A, Siti Humeriah AG, Siti Syarifah MM and Nor Hayati A. Invitro anticancer activity and High-performance liquid chromatography profiles of Aquilaria subnitegra fruit and seed extract. Journal of Tropical forestscience. 2017. 29(2) 208-214.

[7] Giri B, Gomes A, Debnath A, Saha A, Biswas A K Dasgupta S C. Antiproliferative cytotoxic and apoptogenic activity of Indian toad (Bufo melanostictus Schneider) skin extract on U937 and K562 cells. Toxicon. 2006. 48, 388-400.

[8] Mbaveng AT, Kuete V, Mapunya BM, Beng VP, Nkengfeck AE, Meyer JJM, Lall N. Evaluation of four Cameroonian medicinal plants for anticancer, antidiarrheal and anti-reverse transcriptase activities. Environ Toxicol. Pharmacol. 2011. 32, 162-167.

[9] Burstein HJ Schwartz RS. Molecular origins of cancer. N. Engl. J. Med. 2008. 358-527.

[10] Anand P, Kunnumakara AB, Sundaram C, Harikumar KB, Tharakan ST, Lai OS et al Cancer are a preventable disease that requires major lifestyle changes. Pharm res-Ford. 2008. 25(9): 2097-116.

[11] Wong RS. Apoptosis in cancer: from pathogenesis to treatment. J Exp Clin Cancer Res. 2011. 30:87.

[12] Sylvia D, Stuber M, Fung CC, Bazargan-Hejazi S, Cooper E. The knowledge attitudes and use of complementary and alternative medicine in medical students. Evid-Based Compl Alt. 2011.10.1093/ecam/nen075.

[13] Riaz M, Zia-Ul-Haq M, Saas B. Anthocyanins and human health: Bimolecular and therapeutic aspects. Springer, publication. 2016.125-38.

[14] Mahavorasirikul W, Vincent V, Chaijaroenkul W, Itharat Arunporn Na-Bangchang K. BMC complementary and alternative medicine. 2010.10:55 pp 1-8.

[15] Newman D. J and Cragg G. M. Natural products as sources of new drugs over the last 25 year. Journals of natural products. 2007. V 70, 3. Pp 441-467.

[16] Rang H. P, Dale MM, Ritter JM and Moore PK. Pharmacology, Churchill Livingstone, Edinburgh, Scotland. 2007.

[17] Parkin, DM Bray F, Ferlay J, Pisani P. Estimating the world cancer burden: globocan 2000. Int. J. Cancer. 2001.94, 153156.

[18] Russo IH, Russo J. Role of Hormones in mammary cancer initiation and progression. Journal of mammary glands biology and neoplasia. 1998.3, 49-61.

[19] Okada H, Mak TW. Pathway of apoptotic and nonapoptotic death in tumor cells. Nat. Rev Cancer.2004.4: 549-603.

[20] Brown JM, Attardi LD. The role of apoptosis in cancer development and treatment response Nat. Rev Cancer. 2005.5: 231-237.

[21] Cragg GM, Grothaus PG, Newman DJ. Impact of natural products on developing new anticancer agents. Chemicals Reviews 2009, 109, 3012-3043.
[22] Balunas MJ, Kinghorn AD. Drug discovery from medicinal plants. Life science. 2005.78: 431-441.

[23] Waris G, and Ahsan H. Reactive oxygen species: role in the development of cancer and various chronic conditions. Journal of carcinogenesis. 2006.5 articles 14.

[24] Evans M. D, Dizdaroglu and Cooke M S. Oxidative DNA damage and disease: induction repair and significance Mutation Research. 2004.567 no 1 pp 1-61.

[25] Patwardhan B, Vidya AD, Mukund chorghade M. Ayurveda and natural products drug discovery Curr Sci. 2004. 86, 78999.

[26] Philip PA. Experience with docetaxel in the treatment of gastric cancer: Semin Oncol. 2005.32 S24-38.

[27] Kirtikar KR, Basu BD. Indian medicinal plant $3^{\text {rd }}$ ed. Deharadun: 1987. Vol 8 IBC- International book distributor, $p$ 85-89.

[28] Madhri S Pandey G. Some anticancer medicinal plants of foreign origin Curr Sci. 2009. 96: 779-83.

[29] Tan W, Lu J, Huang M, Li Y, Chen M, Wu G, Gong J, Zhong Z, Xu Z, Dang Y, Guo J, Chen X, Wang Y. Anticancer natural products isolated from Chinese medicinal herbs. Chin Med. 2011. 6,27.

[30] Tavakoli J, Miar S, Zadehzare MM, Akbari H. Evaluation of the effectiveness of herbal medication in cancer care: a reviver study. Iran J Cancer Prevention. 2012. 5: 144-156.

[31] Ruamrungsri N, Siengdee P, Sringarm K, Chomdej S, Ongchai $\mathrm{S}$, Nganvongpanit K. Invitro cytotoxic screening of 31 crude extracts of Thai herbs on a chondrosarcoma cell line and primary chondrocytes and apoptotic effects of selected extracts. In vitro cell Dev. Biol- Animal. 2016.52: 434-444.

[32] Hummum YA. Apoptosis and the dilemma of cancer chemotherapy Blood. 1997.89: 1845-1853.

[33] Machine S, Weerapreeyakul N, Barusrux S, Thumanu K, Tanthanuch W. Synergistic anticancer effect of the extracts from Polyalthia evecta caused apoptosis in human hepatoma (HepG2) cells. Asian Pac J Trip Biomed. 2012.2: 589-596.

[34] Safarzadech E, Sandoghchian Shotorbani S, Baradan B. Herbal medicine as inducers of apoptosis in cancer treatment. Adv Pharm Bull. 2014. 4: 421-427.

[35] Sahat AA, Alsaid MS, Kotob SE, Ahamed HH. The significance of Rumex vesicarius as an anticancer remedy against hepatocellular carcinoma: a proposal based on experimental animal studies. Asian Pac J Cancer Prev.2015.16: 4303-4310.

[36] Wang X, Wang N, Cheung F, Lao L, Li C, Feng Y. Chines medicinal for prevention and treatment of human hepatocellular carcinoma: current progress on pharmacological action and mechanism. J integer Med. 2015. 13: $142-164$.

[37] Xiu LJ, Sun DZ, Jiao JP, Yan B, Quin ZF, Liu X, Wei PK, Yue $\mathrm{XO}$. Anticancer affects of traditional Chinese herbs with phlegm eliminating properties- an overview J Ethnopharmacol. 2015. 172: 155-161.

[38] Mukherjee AK, Basu S, Sankar N, Ghosh AC. Advances in cancer therapy with plant-based natural products. Curr Med Chem. 2001. 8: 1467-1486. 
[39] Wang Z, Wang N, Chen J, Shen J. Emerging glycolysis targeting and drug discovery for Chinese medicine in cancer therapy. avid Based Complement Alternat Med. 2012:873-75.

[40] Rather, M. A., B. A. Bhat, and M. A. Quraishi. A multicomponent phytotherapeutic approaches gaining momentum: Is the "one drug model breaking down? Phytomedicine. 2013. 21: 1-14.

[41] Li, S., J. Zhao and B. Yang. Strategies for quality control of Chinese medicines. J. Pharm. Biomed. Anal. 2011. 55: 802809.

[42] Khan MK, Ansari IA, Khan MS. The significance of Rumex vesicarius as an anticancer remedy against hepatocellular carcinoma. Pharmacogn. Mag., 2013, 9, 51-57.

[43] Sun, Chu, Wu, Liu, Antioxidant and antiproliferative activities of common fruits, J of Agri and Food Chem, 50: 2002.74497454 .

[44] Pietta, P. G. Flavonoids in medicinal plants. In C. A. RiceEvans, \& L. Packer (Eds.), Flavonoids in health and disease, New York: Dekker. 1998. pp. 61- 110.

[45] American Cancer Society. Cancer facts \& figures $2015^{\mathrm{b}}$. Atlanta: American Cancer Society; 2014 ${ }^{\mathrm{b}}$.

[46] Uttara B, Singh AV, Zamboni P, Mahajan RT. Oxidative stress and neurodegenerative diseases: A review of upstream and downstream antioxidant therapeutic options. Curr Neuropharmacol. 2009; 7(1):65-74

[47] Campos KC, Rivera JH, Gutierrez JR, Rivera IO, Velev AC, Torres MP, Ortiz MP, Milan CAO. Biological screening of select Puerto Rican plants for cytotoxic and antitumor activities. P R Health Sci J. 2015; 34(1):25-30.

[48] George S, Bhalerao SV, Lidstone EA, Ahmad IS, Abbasi A, Cunningham BT, Watkin KL. Cytotoxicity screening of Bangladeshi medicinal plant extracts on pancreatic cancer cells. BMC Complement Altern Med. 2010; 10(1):1.

[49] Kumar S, Pandey AK. Medicinal attributes of Solanum xanthocarpum fruit consumed by several tribal communities as food: An in vitro antioxidant, anticancer and anti-HIV perspective. BMC Complement Altern Med. 2014; 14(1):112.

[50] Phang CW, Malek SNA, Ibrahim H. Antioxidant potential, cytotoxic activity and total phenolic content of Alpinia pahangensis Rhizomes. BMC Complement Altern Med. 2013; 13(1):243.

[51] Tanih NF, Ndip RN. Evaluation of the acetone and aqueous extracts of mature stem bark of Sclerocarya birreafor antioxidant and antimicrobial properties. Evid Based Complement. Alternat Med. 2012; 1-7.

[52] Efferth T, Kahl S, Paulus K, Adams M, Rauh R, Boechzelt H, Hao X, Kaina B, and Bauer Phytochemistry and pharmacogenomics of natural products derived from traditional Chinese medicine and Chinese material medical with activity against tumor cells. Mol Cancer Ther 2008; 7(1).

[53] Newman DJ, Cragg GM. Natural products as sources of new drugs over the last 25 years. J Nat Prod 2007; 70:461-77.
[54] Zhao RC, Gao HZ, and Qu XJ. Nrf2- ARE signaling pathway and natural products for cancer chemoprevention. Int $\mathrm{J}$ Cancer Epidemiol Detect Prev. 2010; 34:523-533.

[55] Jermal A, Siegel R, Ward E, Hao Y, Xu J and Thun MJ. Cancer statistics. CA Cancer J Clin. 2009; 59:225-249.

[56] Liu HR. Health benefits of fruits and vegetables are from additive and synergistic combinations of phytochemicals. Am J Clin Nutr. 2003; 78:517-520.

[57] American Cancer Society. What is the key statistics about breast cancer? 2015. Available from: http://www.cancer.org/cancer/breastcancer/detailedguide/breas t-cancer-key-statistics.

[58] Jemal, A.; Bray, F.; Center, M. M.; Ferlay, J.; Ward, E.; Forman, D. Global cancer statistics. CA Cancer J. Clin. 2011, 61, 69-90.

[59] Kelsey, J. L.; Berkowitz, G. S. Breast cancer epidemiology. Cancer Res. 1988, 48, 5615-5623.

[60] Zhou, X.; Wang, X.; Huang, Z.; Xu, W.; Liu, P. An ERassociated miRNA signature predicts prognosis in ER-positive breast cancer. J. Exp. Clin. Cancer Res. 2014, 33, 94.

[61] Liu, C. Y.; Hung, M. H.; Wang, D. S.; Chu, P. Y.; Su, J. C.; Teng, T. H.; Huang, C. T.; Chao, T. T.; Wang, C. T.; Shiau, C. W.; et al. Tamoxifen induces apoptosis through cancerous inhibitor of protein phosphatase 2A-dependent phospho-Akt inactivation in estrogen receptor-negative human breast cancer cells Breast Cancer Res. 2014,16, 431.

[62] Mallikharjuna P, Rajanna L, Seetharam Y, Sharanabasappa G (2007) Phytochemical studies of Strychnos potatorum L. f. A medicinal plant. E-J Chem 4: 510-518.

[63] Saad B, Azaizeh H, Said O (2005) Tradition and perspectives of Arab herbal medicine: a review. Evid Based Complement Alternat Med 2: 475-479.

[64] Kasabana S, Hemini S. Medicinal herb index in Indonesia, Bogor, Indonesia. P. T. Eisai, Indonesia. 1998.

[65] Yadav P, R Singh, A review on anthelmintic drugs and their future scope. Int J Pharm Pharm Sci., 2011, 3(3), 17-21.

[66] Mulla MK; P Swamy, Anticancer activity of ethanol and polyphenol extracts of portulacaquadrifidalinn. On human colon cancer cell lines. Int J Pharma \&Bio Sci., 2012,3(3), 488-98.

[67] Hamid Cheshomi, Leila Sadat Aldaghi, and Hasan Rezaei Seresht. Cytotoxicity of the Methanol Extract of Datura innoxia Petals on MCF-7 and HEK-293 Cell Lines J Biomed. 2016.1(2):e6623.

[68] Tamizhazhagan, V, Pugazhendy K, Ethnobotanical and Phytopharmacological review of Pisonia alba Span. Asian J Pharm Clin Res, 2017.10(5), 69-71.

[69] Tamizhazhagan V, Pugazhendy K, Sakthidasan V, Jayanthi C. Antioxidant properties of Pisonia alba plant leaf extract. International Journal of Zoology and Applied Biosciences. 2017; 2(6).311-314. 